\title{
The Effects of Dichotomous Thinking on Depression in Japanese College Students
}

\author{
Takeyasu Kawabata ${ }^{1}$, Naohiko Abe $^{2} \&$ Takafumi Wakai ${ }^{3}$ \\ ${ }^{1}$ Department of Psychology, Shokei Gakuin University, Natori, Japan \\ ${ }^{2}$ Asahigaoka Child Welfare Facility, Kesennuma, Japan \\ ${ }^{3}$ EAP Institute, Kansai University of Welfare Science, Osaka, Japan \\ Corespondence: Takeyasu Kawabata, Department of Psychology, Shokei Gakuin University, Natori, 4-10-1 \\ Yurigaoka, Japan. Tel: 81-22-3813401.
}

Received: November 27, 2020

Accepted: February 14, 2021 Online Published: February 19, 2021

doi:10.5539/jedp.v11n1p28

URL: http://doi.org/10.5539/jedp.v11n1p28

\begin{abstract}
The purpose of this study was to explore the effect of dichotomous thinking on depression. We attempted to test the following hypotheses: 1) dichotomous thinking increases depression, and 2) dichotomous thinking has two routes to increase depression - direct, associative processing, and indirect, reflective processing. Two hundred Japanese college students (Males: 107, Females: 93, M age $=20.02 \pm 1.42$ ) were asked to complete the Dichotomous Thinking Inventory, which consists of three subscales: dichotomous belief, profit-and-loss thinking, and preference for dichotomy; the Kessler 6 Distress Scale; and the Japanese version of the Rumination-reflection Questionnaire. We conducted structural equation modelling to test the hypotheses. The results supported the hypotheses and indicated that dichotomous thinking increased depression. There were two different routes: dichotomous belief directly increased depression and profit-and-loss thinking indirectly increased depression by way of rumination. There are some implications of the findings. This study suggests that cognitive distortions might causes depression from two paths and practical interventions might also have two different routes or approaches to depression.
\end{abstract}

Keywords: dichotomous thinking, depression, rumination, dual process theory, cognitive distortion

\section{Introduction}

Beck's cognitive theory assumes that some individuals may be vulnerable to depression because they develop dysfunctional beliefs as a result of early learning experiences (Beck, 1967). Negative automatic thoughts that dominate the thinking of many depressed persons are sustained through systematic distortions of information processing and contribute to further depression (Scott, 2001). Thus, cognitive distortions are negatively biased errors in thinking that are purported to increase vulnerability to depression (Beck, 1976; Dozois \& Beck, 2008; Acharya \& Relojo, 2017). Cognitive distortions first described by Beck et al. (1979) were expanded by Burns (1980), who identified the following 10 common depressotypic thinking errors: 1) mindreading (i.e., postulating that others are thinking negatively about oneself); 2) catastrophizing (i.e., making negative predictions about the future based on little or no evidence); 3) all-or-nothing thinking (i.e., viewing something as either-or, without considering the full spectrum and range of possible evaluations); 4) emotional reasoning (i.e., believing something to be true based on emotional responses rather than objective evidence); 5) labeling (i.e., classifying oneself negatively after the occurrence of an adverse event); 6) mental filtering (i.e., focusing on negative information and devaluating positive information); 7) overgeneralization (i.e., assuming that the occurrence of one negative event means that additional bad things will happen); 8) personalization (i.e., assuming that oneself is the cause of a negative event); 9) "should" statements (i.e., thinking that things must or should be a certain way); and 10) minimizing or disqualifying the positive (i.e., ignoring or dismissing positive things that have happened).

\subsection{A Dual Process Model of Cognitive Vulnerability to Depression}

Beevers (2005) expanded the cognitive model to propose a dual process model of cognitive vulnerability to depression. Dual process models, which articulates the characteristics of human cognition from a broad framework, have been applied in many areas of psychology and he applied those to the mechanism of depression (Pennycook, 2017). According to dual process theories, humans possess two modes of information processing: an associative 
mode and a reflective mode. The associative mode involves quick, effortless processing based on well-learned associations. The reflective mode involves slow, effortful processing that relies on symbolic, rule-based inferences. Whereas the associative mode occurs automatically, the reflective mode operates when expectancies are disappointed and sufficient cognitive resources are available to respond. In Beevers's (2005) model, a cognitive vulnerability to depression is observed when negatively- biased associative processing is uncorrected by reflective processing. Life stresses appear to deplete the cognitive resources needed for reflective processing to correct negatively biased associative processing. This dual process of self-referent association and cognitive reflection is thought to be important for emotion regulation. Stikkelbroek et al. (2016) found that stress events and symptoms of depression were mediated by maladaptive cognitive emotion regulation strategies.

In recent years, an approach that focuses on the form of cognition, rather than on the content, has been gaining attention as a way to assess dysfunctional thinking. Researchers have theorized that the ability to flexibly engage in a variety of thoughts and behaviors to meet situational demands may be the best indicator of psychological health (Stange et al., 2017). A cognitive style, such as a tendency to respond to stimuli in extreme ways, have been found to predict the relapse of depression (Brouwer et al. 2019; Forand \& DeRubeis, 2014; Teasdale et al., 2001). Forand and DeRubeis (2014) defined extreme responding as the tendency to endorse end-of-scale responses such as "disagree strongly" or "agree strongly" on cognitive questionnaires, such as the Dysfunctional Attitudes Scale (Weissman, 1979). Beevers et al. (2003) have characterized extreme responding as "reflect[ing] rapid, automatic information processing that is uncorrected by subsequent reappraisal" (p. 494). This automatic information processing style has been linked to cognitive biases, including "dichotomous thinking" or "perfectionism" and it is thought to produce extreme cognitive and emotional reactions that confer vulnerability (Beevers et al., 2003; Teasdale et al., 2001). Some studies have indicated that cognitive therapy reduced the relapse of depression via changes in the style rather than the content of thinking (Scott, 2001). For instance, Beck and Alford (2009) insisted that one of the central goals of CBT or cognitive therapy is to improve the patient's ability to think about events in a different light and to make alternative attributions.

\subsection{Dichotomous Thinking and Mental Health}

Dichotomous thinking, one of the depressotypic cognitive biases described above, has also been shown to be linked to negative psychological outcomes other than depression. Beck et al. (1990) indicated that dichotomous thinking has been related to some cluster B personality disorders, such as borderline personality disorder, narcissistic personality disorder, and histrionic personality disorder, and cluster $\mathrm{C}$ personality disorders, such as dependent personality disorder and obsessive-compulsive personality disorder. Dichotomous thinking involves a kind of cognitive rigidity that leads to a polarized perception of reality (e.g., food is either "good" or "bad"). This thinking style has been shown to be an important factor in the maintenance of eating disorders (Antoniou et al., 2017; Fairburn et al., 2003). Dichotomous thinking increases obsessive processing tendencies by stimulating guilt after consuming forbidden foods (Dewberry \& Usher, 1994) and by strengthening their fascination with forbidden foods (Mann \& Ward, 2001). In clinical perfectionism, dichotomous thinking is a major factor in its maintenanceand that it biases individuals' assessment of their own achievement of the standards they demand of themselves (Kothari et al., 2016; Shafran et al., 2002). Thus, dichotomous thinking has been shown to be related to many negative psychological outcomes.

Although knowledge about the relationship between dichotomous thinking and other mental health problems has been collected through empirical research, there is little empirical evidence about the relationship between dichotomous thinking and depression. Oshio (2009) developed the Dichotomous Thinking Inventory (DTI) and demonstrated the reliability and validity of this instrument. DTI consists of three subscales: preference for dichotomy, dichotomous belief, and profit-and-loss thinking. The preference for dichotomy subscale measures a style of thinking that avoids ambiguity and obscurity and that favors distinction and clarity. The Dichotomous Beliefs subscale assesses a way of thinking that believes that everything in the world can be divided into two categories, like right and wrong, instead of being treated as one indivisible thing. The profit-and-loss thinking measures the degree to which a person is motivated by the urge to gain real benefits and avoid disadvantages.

Mieda and Oshio (2015) showed that preference for dichotomy and profit-and-loss thinking of DTI positively correlated with the response time of framing tasks (Kahneman \& Tversky, 1986), whereas dichotomous belief negatively corelated to it. Oshio (2012) concluded that preference for dichotomy and profit-and-loss thinking are reflective modes of cognition, and dichotomous belief is an associative mode of cognition.

The first purpose of this study was to explore the effect of dichotomous thinking on depression, focusing on the functional differences among DTI's subscales. Given Beevers's dual factor model, we hypothesized that dichotomous thinking will directly increase depression as an associative cognitive mode (Hypothesis 1). 


\subsection{Rumination and Depression}

Rumination is a key cognitive or behavioral feature of dysphoria and major depressive disorder (e.g., Olatunji et al., 2013; Nolen-Hoeksema et al., 2008). A number of studies have shown that depressive rumination maintains and exacerbates depressed mood (Nolen-Hoeksema \& Morrow, 1993; Nolen-Hoeksema et al., 1994), and is associated with predicted elevations in levels of depressive symptoms (Abela et al., 2012). Rumination contributes to depression by activating the individual through repeated recall, even after the stressor has ended (Hosseinichimeh et al., 2018). Papageorgiou and Wells (2004) defined ruminative thoughts as follows: (1) associate with the antecedents or nature of negative mood, (2) are not target-directed and do not motivate individuals to create plans to improve the situation, and (3) are not socially shared as long as individuals are involved in rumination. Papageorgiou and Wells (2004) discussed that while negative automatic thoughts are simple, brief evaluations of loss and mistake in depression, rumination consists of a series of self-focused, repetitive, cyclical, negative thoughts that tend to arise as a response to the initial negative thoughts held. Thus, rumination is thought to be an example of Beever's (2005) reflective processing. Therefore, we hypothesized that dichotomous thinking as an associative cognitive mode will increase depression by raising rumination as a reflective cognitive mode (Hypothesis 2). Figure 1 shows our hypothetical model in this study.

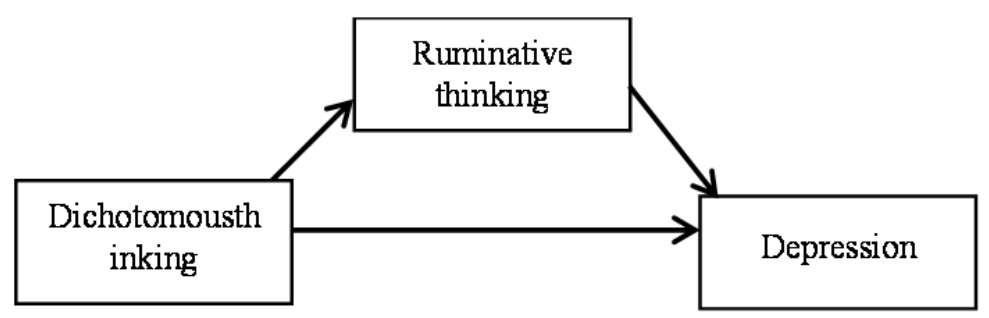

Figure 1. Hypothetical Model

\section{Method}

The Method section describes in detail how the study was conducted, including conceptual and operational definitions of the variables used in the study, Different types of studies will rely on different methodologies; however, a complete description of the methods used enables the reader to evaluate the appropriateness of your methods and the reliability and the validity of your results, It also permits experienced investigators to replicate the study, If your manuscript is an update of an ongoing or earlier study and the method has been published in detail elsewhere, you may refer the reader to that source and simply give a brief synopsis of the method in this section.

\subsection{Participant}

Two hundred Japanese college students participated in the study (Males: 107, Females: 93). All participants were between 18 and 28 years old $(\mathrm{M}$ age $=20.02 ; \mathrm{SD}=1.42)$. They were recruited through lectures as volunteer participants.

\subsection{Procedure}

Participants completed this study in classrooms. Data were collected from September to October 2016. They were asked to fill out the DTI (Oshio, 2009), the Kessler 6 Distress Scale (Furukawa et al., 2003; Kessler et al., 2003;) and the Japanese version of Rumination-reflection Questionnaire (RRQ) (Takano \& Tanno, 2008; Trapnell \& Campbell, 1999).

The study was approved by the Ethical Committee of Human Research, Shokei University (No. 016 - 16). Participants were informed about the study in written and verbal form. They were also informed that the data would be treated with the confidentiality and that they could stop the study at any time if they wanted to. Only those who provided written informed consent were included in the study, including those prior to the initial data collection. Participants were not paid for their participation in the study.

\subsection{Measures}

Dichotomous thinking. The 15-items of the DTI (Oshio, 2009) were used to measure dichotomous thinking style. DTI consists of dichotomous preference (a style of thinking that leads us to prefer explicitness, clarity, and brevity as opposed to ambiguity, obscurity, and uncertainty), dichotomous beliefs (the belief that things in the world can always be divided into two categories, such as "black or white," "success or failure," and "friend or foe"), and 
gain-loss thinking (thinking about how to benefit from a situation and how to avoid disadvantages). The DTI items were scored on a 6-point scale ranging from $1=$ disagree strongly to $6=$ agree strongly. Internal consistency of each DTI subscale was good (preference for dichotomy: $\alpha=.74$, dichotomous belief: $\alpha=.71$, profit-and-loss thinking: $\alpha=.68$ ).

Rumination-reflection. The participants completed the Japanese version of the RRQ (Takano \& Tanno, 2008; Trapnell \& Campbell, 1999). The RRQ is a self-report questionnaire that assesses two forms of self-attentiveness: self-rumination and self-reflection.Self-reflection is a neurotic form of self-attention, and self-reflection is a less neurotic, more openness-related form of self-attention.The RRQ consists of two subscales with 12 items each, ranging from 1 "strongly disagree" to 5 "strongly agree." It is graded on a 5-point scale. The internal consistency of the RRQ was good $(\alpha=.89)$.

Depression. The Japanese version of the Kessler Screening Scale for Psychological Distress (K6) (Kessler et al., 2002; Furukawa et al., 2008) was used to measure depression. Participants were asked to respond to 6 items on a 5 -point rating scale ranging from 1 "all of the time" to 5 "none of the time." The optimal cutoff point on K6 is 9+, with higher scores indicating higher levels of distress. The internal consistency of the K6 was good $(\alpha=.85)$.

Include in the Method section information that provides definitions of all primary and secondary outcome measures and covariates, including measures collected but not included in this report. Describe the methods used to collect data (e.g., written questionnaires, interviews, observations) as well as methods used to enhance the quality of the measurements (e.g., the training and reliability of assessors or the use of multiple observations). Provide information on instruments used, including their psychometric and biometric properties and evidence of cultural validity.

\subsection{Consideration of Human Rights}

In this study, the human rights of participants were protected as follows. The following statements were printed clearly on the face sheet of the questionnaire: "there is no right or wrong answer," "if you do not want to answer some questions, please skip these," "because survey answers are analyzed statistically, each personal answer is not identified," and "the author disposes of all questionnaires responsibility."

\section{Results}

\subsection{Descriptive Statistics and Correlations between Variables}

Descriptive statistics and correlations between all the measures are shown in Table 1 and Table 2. K6 and dichotomous belief were weakly correlated $(\mathrm{r}=.27, \mathrm{p}<.01)$. K6 and profit-and-loss thinking were also weakly correlated $(\mathrm{r}=.14, \mathrm{p}<.05)$. Rumination and profit-and-loss thinking were weakly correlated $(\mathrm{r}=.26, \mathrm{p}<.05)$. Rumination and $\mathrm{K} 6$ were moderately correlated $(\mathrm{r}=.57, \mathrm{p}<.01)$.

Table 1. Descriptive Statistics of All the Measures

\begin{tabular}{lll}
\hline & Mean & $S D$ \\
\hline Preference for dichotomy & 3.68 & 0.87 \\
Dichotomous belief & 2.83 & 0.94 \\
Profit-and-loss thinking & 4.27 & 0.81 \\
K6 & 1.03 & 0.84 \\
Rumination & 3.31 & 0.75 \\
\hline
\end{tabular}

Table 2. Zero Order Correlations of Variables

\begin{tabular}{|c|c|c|c|c|c|c|c|c|c|}
\hline & 1 & & 2 & & 3 & & 4 & & 5 \\
\hline 1 Preference for dichotomy & - & & & & & & & & \\
\hline 2 Dichotomous belief & .47 & ** & - & & & & & & \\
\hline 3 Profit-and-loss thinking & .65 & ** & .32 & ** & - & & & & \\
\hline $4 \mathrm{~K} 6$ & .05 & & .27 & ** & .14 & ** & - & & \\
\hline 5 Rumination & .08 & & .11 & & .26 & ** & .57 & $* *$ & - \\
\hline
\end{tabular}




\subsection{Differences between Depressive and Non-depressive Groups}

Participants were divided into depressive $(n=60)$ and non-depressive groups $(n=140)$ based on the cutoff point of the K6 (9+). Comparing the three DTI subscales and RRQ between the two groups, we found that depressive participants had higher preference for dichotomy, dichotomous belief, profit-and-loss thinking, and rumination scores than non-depressive participants (Table 3).

Table 3. Comparison between High and Low Depressive Groups of Students

\begin{tabular}{llllll}
\hline & Low Depressive & \multicolumn{2}{l}{ High Depressive } & & \multirow{2}{*}{$d f$} \\
\cline { 2 - 3 } & Mean $(S D)$ & Mean $(S D)$ & -2.03 & $*$ & 198 \\
\hline Preference for dichotomy & $3.60(0.85)$ & $3.87(0.90)$ & -4.04 & $* *$ & 198 \\
Dichotomous belief & $2.66(0.88)$ & $3.23(0.97)$ & -2.57 & $*$ & 198 \\
Profit-and-loss thinking & $4.18(0.80)$ & $4.50(0.80)$ & -6.99 & $* *$ & 198 \\
Rumination & $3.09(0.72)$ & $3.82(0.54)$ & & & \\
\hline
\end{tabular}

${ }^{* *} p<.01{ }^{*} p<.05$.

\subsection{Structural Equation Analysis of the Model}

A structural equation analysis based on maximum likelihood estimation (AMOS Ver. 20.0 for Windows, IBM) was applied to the hypothetical model in Figure 1. We entered preference for dichotomy, dichotomous belief, profit-and-loss thinking as dichotomous thinking in Figure 1. By deleting insignificant passes from this initial model, we reached a final model depicted in Figure 2, in which preference for dichotomy only enhanced depression by increasing dichotomous thinking and profit-and-loss thinking, dichotomous belief did not have a path to rumination, and profit-and-loss thinking only enhanced depression by increasing rumination. The overall fitness of the final model was of an acceptable level, as indicated by X2 $(5)=8.40, \mathrm{p}=.14, \mathrm{GFI}=.98, \mathrm{AGFI}=.95$, RMSEA $=.06$.

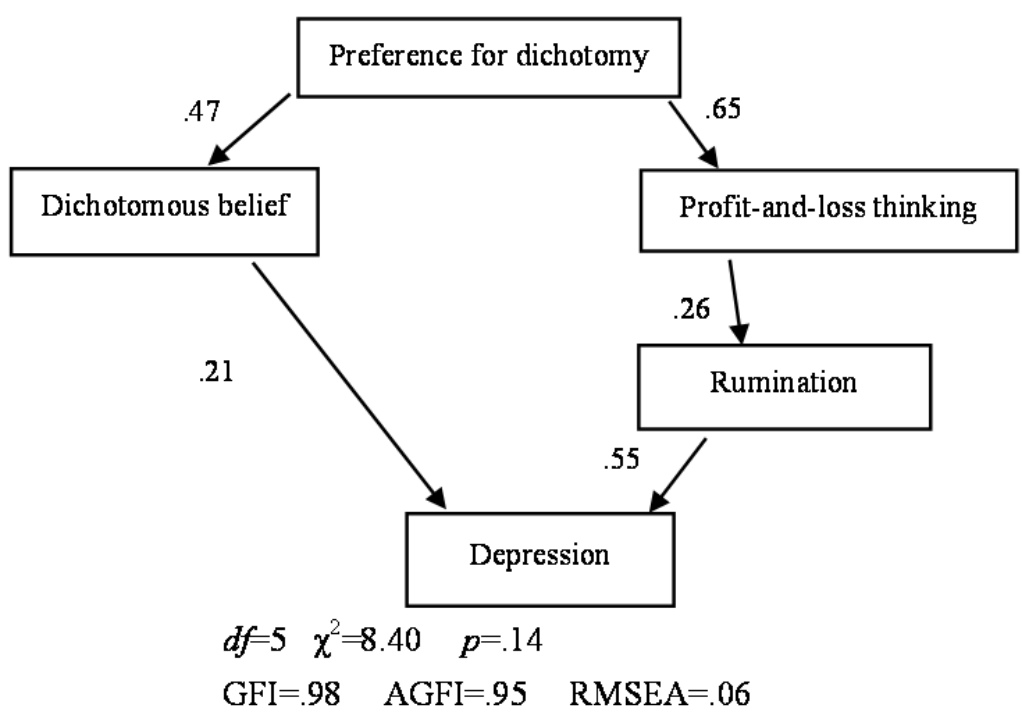

Figure 2. Structural Equation Model of Dichotomous Thinking and Depression

\section{Discussion}

Hypotheses 1 and 2 were both supported: dichotomous thinking enhanced depression in two ways. While dichotomous belief directly enhanced depression, profit-and-loss thinking enhanced depression by increasing rumination. Preference for dichotomy indirectly enhanced depression by increasing dichotomous belief and 
profit-and-loss thinking. The results almost replicated the results of Mieda and Oshio (2015); the difference was that preference for dichotomy was behind dichotomous belief and profit-and-loss thinking, influencing both.

Beevers (2005) pointed out that an associative mode of information processing involves quick, effortless processing, which completes patterns based on associations between the current stimulus and previously encoded stimuli. That is, information that has been previously associated with the salient features of the current stimulus is activated when that stimulus is encountered once again. Thus, past experience facilitates processing of current information. It is similar to belief or schema, which aids in interpreting how the world or things are. The items of dichotomous belief also indicate how "anything" in the world can be divided into two categories: black or white, good or bad, or winner or loser. Therefore, the results illustrated that dichotomous belief directly increased depression as an associative mode.

Profit-and-loss thinking consists of items that ask for the meaning of the events relating to oneself. Oshio (2012) suggested that profit-and-loss thinking represents focusing on one's own benefits and advantages, and people with this thinking style may avoid disadvantages. Therefore, individuals who obtains a high score in profit-and-loss thinking are likely to focus their attention on themselves. Trapnell and Campbell (1999) divided self-attention into rumination and reflection. Thus, it is possible that profit-and-loss thinking, which contains the activation of a kind self-focusing, increased rumination. Rumination is known to cause and maintain depression (McLaughlin \& Nolen-Hoeksema, 2011). Hence, it is plausible that profit-and-loss thinking as a kind of perfectionism enhances depression by increasing rumination.

Preference for dichotomy indirectly increased depression by increasing the other two subscales of DTI. This result suggests that preference for dichotomy is a core schema of dichotomous thinking. However, further investigation is needed.

The relationship between dichotomous thinking and depression has also been indicated in the context of perfectionism. The perfectionism-depression link has been widely demonstrated (Flett et al., 2003; Hewitt \& Flett, 1991). Ferrari et al. (2018) regarded perfectionism as a primary mechanism underpinning the development and maintenance of depression. Several studies have documented that dichotomous thinking is associated with perfectionism. Shafran et al. (2002) associated dichotomous thinking with perfectionism in their perfectionism model. They showed that dichotomous thinking is a central factor maintaining perfectionism. Oshio (2009) suggested that the three subscales of DTI relate to perfectionism in different ways: the profit-and-loss subscale is associated with both positive and negative aspects of perfectionism; the preference for dichotomy subscale may be related to the positive aspects of perfectionism; and the dichotomous belief subscale is associated with the negative aspects of perfectionism. According to our results, dichotomous belief directly increased depression, while profit-and-loss thinking indirectly increased depression. Harris et al. (2008) demonstrated that rumination mediated the relationship between maladaptive perfectionism and depressive symptoms. If the profit-and-loss subscale measures rumination due to obsession, negative aspects of perfectionism might increase depression.

The present study revealed that there are two routes by which cognitive distortions can cause depression, and from this it can be suggested that practical interventions for the amelioration of depression may also require different approaches, corresponding to these two different pathways. It is also possible that the dysfunctional areas may differ among patients who show symptoms of depression.

This study was based on a self-completed questionnaire by Japanese college students. We need to replicate our results in more experimental situations in which conditions are strictly controlled. It is also necessary to expand our results regarding the age and socioeconomic status of participants to assess the generalizability of our findings.

\section{References}

Abela, J. R., Hankin, B. L., Sheshko, D. M., Fishman, M. B., \& Stolow, D. (2012). Multi-wave prospective examination of the stress-reactivity extension of response styles theory of depression in high-risk children and early adolescents. Journal of abnormal child psychology, 40(2), 277-287. https://doi.org/10.1007/s10802-011-9563-x

Acharya, S., \& Relojo, D. (2017). Examining the role of cognitive distortion and parental bonding in depressive symptoms among male adolescents: A randomised crossover trial. Journal of Innovation in Psychology, Education and Didactics, 21(1), 7-20. https://doi.org/10.5281/zenodo.1289149.

Antoniou, E. E., Bongers, P., \& Jansen, A. (2017). The mediating role of dichotomous thinking and emotional eating in the relationship between depression and BMI. Eating behaviors, 26, 55-60. http://doi.org/10.1016/j.eatbeh.2017.01.007 
Beck, A. T. (1967). Depression: Clinical, experimental, and theoretical aspects. Harper and Row.

Beck, A. T. (1976). Cognitive therapy and the emotional disorders. Penguin.

Beck, A. T., \& Alford, B. A. (2009). Depression: Causes and treatment (2nd ed.). Philadelphia: University of Pennsylvania Press. https://doi.org/10.9783/9780812290882

Beck, A. T., Freeman, A., Davis, D. D., \& Associates. (1990). Cognitive therapy of personality disorders. Guilford.

Beck, A. T., Rush, A. J., Shaw, B. F., \& Emery, G. (1979). Cognitive therapy of depression. Guilford.

Beevers, C. G. (2005). Cognitive vulnerability to depression: A dual process model. Clinical Psychology Review, 25(7), 975-1002. https://doi.org/10.1016/j.cpr.2005.03.003

Beevers, C. G., Keitner, G. I., Ryan, C. E., \& Miller, I. W. (2003). Cognitive predictors of symptom return following depression treatment. Journal of Abnormal Psychology, 112(3), 488-496. https://doi.org/10.1037/0021-843X.112.3.488

Brouwer, M. E., Williams, A. D., Forand, N. R., DeRubeis, R. J., \& Bockting, C. L. (2019). Dysfunctional attitudes or extreme response style as predictors of depressive relapse and recurrence after mobile cognitive therapy for recurrent depression. Journal of affective disorders, 243, 48-54. https://doi.org/10.1016/j.jad.2018.09.002

Burns, D. D. (1980). Feeling good: The mood therapy book. New American Library.

Dewberry, C., \& Ussher, J. M. (1994). Restraint and perception of body weight among British adults. The Journal of Social Psychology, 134(5), 609-619. https://doi.org/10.1080/00224545.1994.9922991

Dozois, D. J. A, \& Beck, A. T. (2008). Cognitive schemas, beliefs and assumptions. In K. S. Dobson \& D. J. A. Dozois (Eds.), Risk factors in depression (pp. 121-142). Elsevier. https://doi.org/10.1016/B978-0-08-045078-0.00006-X

Fairburn, C. G., Cooper, Z., \& Shafran, R. (2003). Cognitive behaviour therapy for eating disorders: A "transdiagnostic" theory and treatment. Behaviour Research and Therapy, 41(5), 509-528. https://doi.org/10.1016/S0005-7967(02)00088-8

Ferrari, M., Yap, K., Scott, N., Einstein, D. A., \& Ciarrochi, J. (2018). Self-compassion moderates the perfectionism and depression link in both adolescence and adulthood. PloS ONE, 13(2), e0192022. https://doi.org/10.1371/journal.pone.0192022

Flett, G. L., Besser, A., Davis, R. A., \& Hewitt, P. L. (2003). Dimensions of perfectionism, unconditional self-acceptance, and depression. Journal of Rational-Emotive and Cognitive-Behavior Therapy, 21(2), 119-138. https://doi.org/10.1023/A:1025051431957

Forand, N. R., \& DeRubeis, R. J. (2014). Extreme response style and symptom return after depression treatment: the role of positive extreme responding. Journal of Consulting and Clinical Psychology, 82(3), 500-509. https://doi.org/10.1037/a0035755

Furukawa, T. A., Kawakami, N., Saitoh, M., Ono, Y., Nakane, Y., Nakamura, Y., ... \& Watanabe, M. (2008). The performance of the Japanese version of the K6 and K10 in the World Mental Health Survey Japan. International journal of methods in psychiatric research, 17(3), 152-158. https://doi.org/10.1002/mpr.257

Furukawa, T. A., Kessler, R. C., Slade, T., \& Andrews, G. (2003). The performance of the K6 and K10 screening scales for psychological distress in the Australian National Survey of Mental Health and Well-Being. Psychological Medicine, 33(2), 357-362. https://doi.org/10.1017/S0033291702006700

Harris, P. W., Pepper, C. M., \& Maack, D. J. (2008). The relationship between maladaptive perfectionism and depressive symptoms: The mediating role of rumination. Personality and Individual Differences, 44(1), 150-160. https://doi.org/10.1016/j.paid.2007.07.011

Hewitt, P. L., \& Flett, G. L. (1991). Dimensions of perfectionism in unipolar depression. Journal of Abnormal Psychology, 100(1), 98-101. https://doi.org/10.1037/0021-843X.100.1.98

Hosseinichimeh, N., Wittenborn, A. K., Rick, J., Jalali, M. S., \& Rahmandad, H. (2018). Modeling and estimating the feedback mechanisms among depression, rumination, and stressors in adolescents. PloS one, 13(9), e0204389. https://doi.org/10.1371/journal.pone.0204389

Kahneman, D., \& Tversky, A. (1986). Rational choice and the framing of decisions. Journal of Business, 59(4), 251-278. https://doi.org/10.1086/296365 
Kessler, R. C., Andrews, G., Colpe, L. J., Hiripi, E., Mroczek, D. K., Normand, S. L., Walters, E. E., \& Zaslavsky, A. M. (2002). Short screening scales to monitor population prevalences and trends in non-specific $\begin{array}{llll}\text { psychological distress. } & \text { Psychological }\end{array}$ https://doi.org/10.1017/S0033291702006074

Kothari, R., Egan, S., Wade, T., Andersson, G., \& Shafran, R. (2016). Overcoming perfectionism: protocol of a randomized controlled trial of an internet-based guided self-help cognitive behavioral therapy intervention. JMIR research protocols, 5(4), e215. https://doi.org/10.2196/resprot.6378

Mann, T., \& Ward, A. (2001). Forbidden fruit: Does thinking about a prohibited food lead to its consumption? International Journal of Eating Disorders, 29(3), 319-327. https://doi.org/10.1002/eat.1025

McLaughlin, K. A., \& Nolen-Hoeksema, S. (2011). Rumination as a transdiagnostic factor in depression and anxiety. Behaviour Research and Therapy, 49(3), 186-193. https://doi.org/10.1016/j.brat.2010.12.006

Mieda, \& Oshio. (2015, September). [Effects of dichotomous thinking on risk aversion.] Nibunnhoutekisikou ga sonnsitukaihikeikou ni oyobosu eikyo. Paper presented at the 79th Annual convention of the Japanese Psychological Association, Nagoya, Nagoya. https://doi.org/10.4992/pacjpa.79.0_3PM-006

Nolen-Hoeksema, S., \& Morrow, J. (1993). Effects of rumination and distraction on naturally occurring depressed mood. Cognition and Emotion, 7(6), 561-570. https://doi.org/10.1080/02699939308409206

Nolen-Hoeksema, S., Parker, L. E., \& Larson, J. (1994). Ruminative coping with depressed mood following loss. Journal of Personality and Social Psychology, 67(1), 92-104. https://doi.org/10.1037/0022-3514.67.1.92

Nolen-Hoeksema, S., Wisco, B. E., \& Lyubomirsky, S. (2008). Rethinking rumination. Perspectives on Psychological Science, 3(5), 400-424. https://doi.org/10.1111/j.1745-6924.2008.00088.x

Olatunji, B. O., Naragon-Gainey, K., \& Wolitzky-Taylor, K. B. (2013). Specificity of rumination in anxiety and depression: A multimodal meta-analysis. Clinical Psychology: Science and Practice, 20(3), 225-257. https://doi.org/10.1111/cpsp.12037

Oshio, A. (2009). Development and validation of the dichotomous thinking inventory. Social Behavior and Personality: An International Journal, 37(6), 729-741. https://doi.org/10.2224/sbp.2009.37.6.729

Oshio, A. (2012). Dichotomous thinking leads to entity theories of human ability. Psychology Research, 2(6), 369-375. https://doi.org/10.17265/2159-5542/2012.06.005

Papageorgiou, C., \& Wells, A. (2004). Nature, functions, and beliefs about depressive rumination. In Papageorgiou, C., \& Wells, A. (Eds.), Depressive rumination: Nature, theory and treatment (pp. 1-20). John Wiley \& Sons. https://doi.org/10.1002/9780470713853.ch1

Pennycook, G. (2017). A perspective on the theoretical foundation of dual-process models. In W. De Neys (Ed.). Dual Process Theory 2.0. Oxon, UK: Routledge. https://doi.org/10.4324/9781315204550-2

Scott, J. (2001). Cognitive therapy for depression. British Medical Bulletin, 57(1), 101-113. https://doi.org/10.1093/bmb/57.1.101

Shafran, R., Cooper, Z., \& Fairburn, C. G. (2002). Clinical perfectionism: A cognitive-behavioural analysis. Behaviour Research and Therapy, 40(7), 773-791. https://doi.org/10.1016/S0005-7967(01)00059-6

Stange, J. P., Alloy, L. B., \& Fresco, D. M. (2017). Inflexibility as a vulnerability to depression: A systematic qualitative review. Clinical Psychology: Science and Practice, 24(3), 245-276. https://doi.org/10.1111/cpsp.12201

Stikkelbroek, Y., Bodden, D. H., Kleinjan, M., Reijnders, M., \& van Baar, A. L. (2016). Adolescent depression and negative life events, the mediating role of cognitive emotion regulation. PloS one, 11(8), e0161062. https://doi.org/10.1371/journal.pone.0161062

Takano, K., \& Tanno, Y. (2008). [Development of Japanese-version Rumination-Reflection Questionnaire.] Rumination-Reflection Questionnaire nihongoban sakusei no kokoromi (in Japanese). Personality kenkyu (The Japanese Journal of Personality), 16(2), 259-261. https://doi.org/10.2132/personality.16.259

Teasdale, J. D., Scott, J., Moore, R. G., Hayhurst, H., Pope, M., \& Paykel, E. S. (2001). How does cognitive therapy prevent relapse in residual depression? Evidence from a controlled trial. Journal of Consulting and Clinical Psychology, 69(3), 347-357. https://doi.org/10.1037/0022-006X.69.3.347

Trapnell, P. D., \& Campbell, J. D. (1999). Private self-consciousness and the five-factor model of personality: distinguishing rumination from reflection. Journal of Personality and Social Psychology, 76(2), 284-304. 
https://doi.org/10.1037/0022-3514.76.2.284

Weissman, A. N. (1979). The dysfunctional attitude scale: A validation study [Unpublished doctoral dissertation]. University of Pennsylvania. https://doi.org/10.1037/t00091-000

\section{Copyrights}

Copyright for this article is retained by the author(s), with first publication rights granted to the journal.

This is an open-access article distributed under the terms and conditions of the Creative Commons Attribution license (http://creativecommons.org/licenses/by/4.0/). 